\title{
AS LINGUAGENS DO NOVO CAPITALISMO: os casos exemplares da Endeavor Brasil, Artemisia e Ashoka Brasil
}

\author{
THE LANGUAGES OF THE NEW CAPITALISM: \\ the exemplary cases of Endeavor Brasil, Artemisia and Ashoka Brasil
}

\author{
Alexandre Barbalho* \\ Carolina do Vale Uchoa*
}

\begin{abstract}
Resumo
Este artigo analisa o fenômeno do empreendedorismo social no Brasil, procurando percebê-lo como um ambiente de negociações e disputas do capitalismo contemporâneo, a partir dos discursos de três organizações consideradas exemplares desse campo: Endeavor Brasil, Artemisia e Ashoka Brasil. Para análise da construção discursiva, selecionamos textos que foram publicados nos sites das três organizações e que pretendem funcionar como manuais, oferecendo orientações aos empreendedores sociais. Como suporte teórico-metodológico, adotamos a Análise Crítica do Discurso.
\end{abstract}

Palavras-Chave: Empreendedorismo. Organização. Capitalismo. Discurso.

\begin{abstract}
This article analyzes the phenomenon of social entrepreneurship in Brazil, seeking to perceive it as an environment of negotiations and disputes of contemporary capitalism, from the speeches of three organizations considered exemplars of this field: Endeavor Brazil, Artemisia and Ashoka Brazil. For the analysis of the discursive construction, we selected texts that were published on the websites of the three organizations and intended to function as manuals, offering guidance to social entrepreneurs. As a theoretical-methodological support, we adopted the Critical Discourse Analysis.
\end{abstract}

Keywords: Entrepreneurship. Organization. Capitalism. Discourse.

\section{Introdução}

A expressão "empreendedorismo social" tornou-se relativamente usual no Brasil integrando uma tendência global, posto que, desde os anos 1990, o termo "social entrepreneurship" passou a fazer parte da literatura de management e do mundo corporativo (DEES, 1998; DEY; STEYAERT, 2010; HERVIEUX; GEDAJLOVIC; TURCOTTE, 2010). A receptividade do termo e a forma trivial como costuma ser empregado na mídia podem transmitir a impressão de que seus significados são claros e livres de tensões, frisando seu potencial para "mudar o mundo" (CASAQUI, 2016a, 2016b). Mas, como tema emergente, caracteriza-se antes, como afirmam Parente e Barbosa, "por uma significativa proliferação e polimorfismo de designações e significados" (PARENTE; BARBOSA, 2011, p. 2).

\footnotetext{
* Possui licenciatura em História pela Universidade Estadual do Ceará (UECE), bacharelado em Ciências Sociais e mestrado em Sociologia pela Universidade Federal do Ceará (UFC) e doutorado em Comunicação e Cultura Contemporâneas pela Universidade Federal da Bahia (UFBA). Estágio pós-doutoral em Comunicação na Universidade Nova de Lisboa. É professor adjunto do curso de História e dos PPGs em Sociologia e em Políticas Públicas da UECE e em Comunicação da UFC. E-mail: alexandrealmeidabarbalho@gmail.com

** Possui bacharelado em Comunicação Social com habilitação em Jornalismo pela Universidade Federal do Ceará (UFC) e mestrado em Sociologia pela Universidade Estadual do Ceará (UECE). E-mail: dovale.carol@gmail.com
} 
A despeito da falta de consenso sobre seu significado, o empreendedorismo social costuma ser definido como o emprego de métodos e técnicas de gestão empresarial para a criação e desenvolvimento de soluções inovadoras para problemas sociais. Sob a ótica dos empreendedores, o setor apresenta-se como a combinação entre lucro e sustentabilidade financeira e o propósito de contribuir com transformações positivas na sociedade. Seu crescimento é associado ainda a formas eficazes de dinamizar a economia por meio da abertura de novos mercados e da criação de novas carreiras profissionais e promoção do "autoemprego".

No entanto, os discursos promotores do empreendedorismo social ainda não têm sido acompanhados pela ampliação de repertório crítico capaz de examinar suas potencialidades e explicitar seus limites, ainda que Michel Foucault, por exemplo, tenha exposto a íntima relação entre o neoliberalismo norte-americano e o empreendedor de si, o homo oeconomicus, em seu curso sobre o nascimento da biopolítica no Collège de France nos anos 1978 e 1979. Foucault (2004) aponta que, apesar do contexto de surgimento do neoliberalismo nos Estados Unidos ser semelhante aos da Alemanha e da França, ou seja, de reação ao incremento da presença do Estado na sociedade, há diferenças fundamentais entre o projeto neoliberal "à americana" em relação ao "à europeia".

Segundo o pensador francês, o modelo norte-americano, mais do que uma "técnica dos governantes direcionada aos governados", como seria o caso europeu, se refere a "toda uma maneira de ser e de pensar", a um "tipo de relação entre governantes e governados". Isto implica uma "espécie de reivindicação global", de "foco utópico", e um "método de pensamento", uma "grade de análise econômica e sociológica" (FOUCAULT, 2004, p. 224 - tradução livre). Em outras palavras, nos EUA o neoliberalismo assume o modo de uma utopia liberal com estilo próprio de pensamento, de análise e de imaginação. Pode-se afirmar, a partir de autores que vão desenvolver ou dialogar com a linha de pensamento foucaultiana como Negri e Lazaratto (2013), Gros (2018) e Gorz (2005), entre outros, que, com a desterritorialização do capital, esta utopia liberal própria à sociedade norte-americana, da qual o empreendedorismo social seria uma expressão, apresenta-se como global ${ }^{1}$.

Este artigo, portanto, soma-se aos esforços analíticos sobre o fenômeno do empreendedorismo social, procurando percebê-lo como um ambiente de negociações e disputas. A questão que nos orienta é: como se dá a constituição discursiva do empreendedorismo social e a elaboração das representações sociais nas quais os agentes envolvidos se apoiam para justificar suas ações?

Para darmos conta da problemática proposta, analisamos os discursos de três organizações de apoio ao empreendedorismo social que desenvolvem uma ampla gama de atividades (formação, investimento e financiamento direto, difusão de conhecimentos e informações): Endeavor Brasil, Artemisia e Ashoka Brasil. A escolha deveu-se ao seu caráter pioneiro, bem

1Atualizar a investigação acerca das ligações entre empreendedorismo de si, neoliberalismo e biopolítica feita por Foucault no final dos anos 1970 é uma linha promissora de análise a ser desenvolvida em pesquisas posteriores. 
como à visibilidade de que desfrutam, alcançando uma grande quantidade de "seguidores" em suas redes sociais e atraindo números significativos de interessados para os programas que desenvolvem.

Estar ligado a essas instituições garante uma espécie de chancela ou "selo" para os empreendedores: eles passam a ser reconhecidos como "Case Endeavor", "Empreendedor Artemisia", "Fellow Ashoka”. Essas organizações ajudam tanto a criar as identidades sociais dos agentes já inseridos no campo como buscam mostrar, para aqueles que estão "de fora", quais são os investimentos, atributos e esforços necessários para entrar e alcançar as posições mais destacadas, bem como as vantagens que essas posições proporcionam.

Selecionamos, para análise, textos que foram publicados nos sites dessas três organizações e que pretendem funcionar como pequenos guias ou manuais, oferecendo orientações para aqueles que sonham em se tornar empreendedores sociais ou para aqueles que buscam melhorar seu desempenho. Como suporte teórico-metodológico, adotamos a Análise Crítica do Discurso desenvolvida, principalmente, por Norman Fairclough (2001), que apresentamos na seção a seguir.

\section{Mudança discursiva e mudança social na Análise Crítica do Discurso}

A Análise Crítica do Discurso (ACD) é uma das ramificações do instrumental teóricometodológico voltado para o estudo das relações entre o discurso e outras práticas sociais, buscando situá-las nas transformações que marcam a vida contemporânea, combinando análise linguística, crítica social e análise sócio-histórica. Para isso, deve-se considerar que o discurso necessariamente se realiza dentro das restrições impostas pelas estruturas sociais e no interior de relações e lutas de poder particulares (IRIGARAY; CUNHA; HARTEN, 2016; FAIRCLOUGH, 2001).

Fairclough (2001) propõe um modelo que estuda o discurso como fenômeno tridimensional, considerado, simultaneamente, como prática textual, prática discursiva e prática social. É por meio desse tripé que ele busca reunir a análise linguística, a tradição macrossociológica de análise da prática social em relação às estruturas sociais e a tradição microssociológica ou interpretativa que focaliza a prática dos agentes em contextos situacionais e com base em um senso comum compartilhado.

Seguindo seu projeto de desenvolver modelos de análise que permitam compreender a complexidade das mudanças sociais contemporâneas, Fairclough tem se voltado, em seus trabalhos mais recentes, para as linguagens do capitalismo, do neoliberalismo e da globalização. Em 2002, ele publicou com Ève Chiapello um artigo em que propõem um modelo de pesquisa transdisciplinar para a investigação da ideologia gerencial. Tomaremos esse modelo como referência metodológica para o desenvolvimento da parte empírica desta pesquisa. Chiapello e Fairclough (2002) analisam um dos capítulos do livro E-volve! Succeeding in the digital culture of 
tomorrow, que se tornou um best-seller da literatura de gestão empresarial. Nesse estudo, o "novo espírito do capitalismo", tal como desenvolvido por Boltanski e Chiapello (2009), é considerado como uma "ordem de discurso", ou seja, uma configuração de discursos articulados de maneira particular, dialeticamente representados como modos de agir e inculcados como formas de ser ou identidades sociais. E, como ordem de discurso, compõe-se de vocabulário e de "gramática" próprios. Nessa perspectiva, a análise não deve se preocupar apenas em identificar os elementos léxicos e semânticos que compõem o discurso, mas principalmente em compreender como os valores, implícitos ou explícitos, que eles carregam contribuem para disseminar o espírito do capitalismo.

A partir da análise do texto em questão, os autores buscam responder a três questões interligadas, mas analiticamente separáveis, que correspondem, respectivamente, às dimensões relacionais, identitárias e ideacionais da linguagem: (1) de qual o tipo de atividade e de interação social o discurso é parte?; (2) que tipo de identidade autoral é constituída?; (3) que tipos de representações são feitas dos agentes e de suas práticas? Trata-se de compreender, em primeiro lugar, como aquele discurso participa de outras práticas sociais. O segundo ponto visa a perceber como é definida a identidade do autor do discurso. Além dos atributos que podem ser explicitamente mencionados no texto - como a trajetória do autor -, essas representações podem ser percebidas também nos aspectos semânticos e léxico-gramaticais dos textos: a presença de afirmações categóricas, de caráter normativo ou prescritivo, por exemplo, indica a autoridade do expert não só para dizer o que deve ser feito, mas também para antecipar acontecimentos, identificando as "tendências" de futuro.

Já na terceira pergunta o esforço é o de identificar quais são os princípios de equivalência e de oposição utilizados para diferenciar os "grandes" dos "pequenos". Esses discursos carregam consigo valores que podem ser explicitados, mas, na maior parte das vezes, permanecem implícitos e se baseiam na suposição de que são compartilhados pelos leitores. Além disso, busca-se perceber como respondem às três dimensões de legitimação identificadas por Boltanski e Chiapello (2009): estímulo, segurança e justiça. A promessa de estímulo evoca um mundo de mudança, de inovação, de criatividade, de liberdade e desenvolvimento pessoal. A promessa de segurança pode estar ligada, por exemplo, à proteção que o líder dá à equipe e a promessa de justiça ao reconhecimento social que as pessoas podem obter a partir do seu engajamento no trabalho.

O modelo de análise proposto permite, portanto, analisar os discursos da "nova ideologia empresarial" - de que são partes integrantes e importantes os discursos acerca do empreendedorismo social - como uma prática social, buscando compreender como se relacionam, em sua produção, circulação e recepção, com outras práticas sociais, inseridas em um contexto sociopolítico mais amplo; como prática discursiva, forjada em contextos institucionais e situacionais específicos; e como prática textual, considerando, por exemplo, os "vocabulários" utilizados para descrever os atributos próprios dos empreendedores sociais e as relexicalizações 
e significações que marcam os processos de mudança discursiva e social. Mostra-se relevante também atentar para a identidade autoral dos discursos, em que se baseia sua "autoridade"; as representações que são construídas de práticas e agentes; os princípios segundo os quais essas práticas são julgadas e como os agentes são avaliados, e em que regimes de justificação mais amplos essas avaliações se inserem.

A partir do que foi estabelecido, investigaremos, na próxima seção, as formações discursivas acerca do empreendedorismo social. Antes se faz necessário retomar o debate acerca do "novo espírito do capitalismo", citado acima, de modo a situar o contexto sócio-histórico de emergência do empreendedorismo social. Em sua obra, Boltanski e Chiapello (2009) analisam as transformações que vêm ocorrendo nas sociedades capitalistas desde o fim de 1960 até meados de 1990. Para os autores, o capitalismo assimila ideias que lhe são estranhas e até hostis, mantendo, porém, intacta sua finalidade primordial (a acumulação do capital). No final dos anos 1960, essas críticas tinham como alvo sobretudo a alienação, o desencantamento e a desumanização sob o império da técnica, bem como os efeitos desmotivadores dos regimes excessivamente burocratizados e hierarquizados das grandes empresas.

Os capitalistas tiveram que ceder à pressão das críticas, adotando formas de trabalho mais autônomas. Isso foi feito por meio de mudanças na organização do trabalho e nos processos produtivos, que acabaram por se mostrar vantajosas para os proprietários, pois, substituindo o controle pelo autocontrole, livraram-se dos elevados custos de supervisão, transferindo o peso da organização para os assalariados. Como afirma Gorz (2005), os empregados têm de se tornar empresas que devem responder pela rentabilidade de seu trabalho, internalizando a pressão trazida pela lógica da obtenção do máximo proveito possível e se responsabilizando por sua própria formação, aperfeiçoamento, saúde etc.

Além disso, a empresa pode colocar-se em contraste com as instituições que ainda se mantinham apegadas às formas hierárquicas (como, por exemplo, governos, sindicatos e partidos), impondo sua superioridade sobre estas e se apresentando como diversificada, móvel, diferenciada e, por isso, o lugar privilegiado da inovação social, da imaginação criadora, da livre iniciativa. A flexibilização passa a ser vista como uma necessidade, um processo inelutável de adaptação a novas situações, como a globalização, a abertura dos mercados, mudanças nos hábitos de consumo, diversificação da demanda etc. A autogestão, o autocontrole e a horizontalidade passam a ser os princípios gerais, exaltados nesse novo modelo. Valoriza-se sobretudo a "capacidade de tirar proveito dos conhecimentos mais diversificados, de interpretálos e combiná-los, de criar e de pôr em circulação inovações e, mais geralmente, de manipular símbolos" (BOLTANSKI; CHIAPELLO, 2009, p. 104).

De acordo com esse princípio, a própria vida passa a ser concebida como uma sequência de projetos, sendo que quanto mais o atual difere do anterior, mais valioso ele se torna. É fundamental estar sempre buscando novas atividades, nunca estar sem um projeto, sem uma ideia em mente, estar sempre se preparando para fazer algo junto com outras pessoas, com quem se 
estabelece um vínculo provisório, articulado em torno de uma atividade específica. Esse modelo de gestão, que se estende para um modelo de conduta de vida, está fortemente presente nos discursos do empreendedorismo social, como veremos na próxima seção. Os atributos daqueles que se "encaixam no perfil" desse tipo de negócio são a criatividade, a autonomia e a autogestão, a flexibilidade para se adaptar a diferentes situações e estar sempre "aberto à mudança" e, sobretudo, a capacidade de fazer usos estratégicos das redes de contatos pessoais para motivar e engajar outras pessoas em seus projetos. Essas qualidades fazem com que os empreendedores sociais, frequentemente apresentados como líderes inspiradores e visionários, estejam sempre dispostos a "quebrar paradigmas" e implantar novos métodos de condução e organização dos seus negócios, ocupando, portanto, uma posição de vanguarda no meio empresarial, que se torna um espaço de experimentação.

Em chave analítica próxima, para Dardot e Laval (2016), o empreendedorismo - e a figura do empreendedor, ou homem-empresa, como chamam - é o princípio de conduta mais essencial à ordem capitalista (sobretudo na corrente neoliberal inaugurada por Ludwig von Mises e Friedrich von Hayek), constituindo sua dimensão antropológica. Assim, na visão neoliberal, afirmam os autores, mais do que a construção de uma situação econômica que se aproxime do cânone da livre concorrência, é necessário haver uma política que diz respeito à totalidade da ação humana, que visa moldar os sujeitos para torná-los empreendedores que saibam aproveitar as oportunidades de lucro e estejam dispostos a entrar no processo permanente da concorrência.

Diante desse contexto, para que o fenômeno do empreendedorismo social pudesse emergir e ganhar forma no início do século XXI, ele precisava se apresentar como resposta a demandas e interesses (não apenas econômicos) de determinados grupos sociais, convergindo com as "visões de mundo" e condutas de vida próprias ao novo espírito do capitalismo. Esse processo se dá, sobretudo, pela elaboração e difusão de discursos capazes de evidenciar suas virtudes e anunciar recompensas oferecidas aos que se disponham a se engajar em suas atividades, por meio de exemplos que sirvam como modelo e inspiração.

Nossa análise buscará perceber como se formam os discursos hegemônicos sobre o empreendedorismo social, ou seja, aqueles discursos que alcançam ampla difusão na sociedade, propagando, por diversos meios, uma representação geral de suas práticas e seus valores. Para isso, selecionamos, como dito na introdução, três instituições que desempenham papéis preponderantes nesse campo (Endeavor Brasil, Ashoka Brasil e Artemisia).

A escolha dessas três instituições se deve ao seu papel precursor e fundamental na divulgação do empreendedorismo social no Brasil: todas dispõem de portais e outras plataformas digitais para difusão de conteúdos, além de desenvolverem publicações e realizarem atividades com o propósito de estimular o setor e também de interferir na distribuição de poder e capital simbólicos, ajudando a ditar a dinâmica das relações de forças atuantes nesse campo. Além disso, essas instituições oferecem uma série de serviços que não apenas cumprem a função de orientar sobre as melhores técnicas gerenciais, mas fornecem modelos de condutas gerais e ajudam a 
moldar os discursos dos empreendedores sociais, fornecendo "vocabulários de motivos" com os quais esses possam construir narrativas coerentes de suas trajetórias de vida.

Nossa análise irá concentrar-se nos discursos produzidos por essas três instituições buscando examiná-los com base nos três critérios apontados no modelo de análise transdisciplinar citado anteriormente: (1) identificar de que práticas sociais esses discursos participam, ou seja, como figuram na atuação geral dessas organizações e como as auxiliam a alcançar seus objetivos; (2) verificar como constroem sua identidade autoral e como definem seu próprio papel e sua autoridade nesse campo e a identidade social dos receptores de seus discursos; e (3) examinar as representações que constroem acerca do próprio empreendedorismo social.

\section{O empreendedorismo social segundo Endeavor Brasil, Artemisia e Ashoka Brasil}

Os textos que iremos analisar ${ }^{2}$ foram publicados nos sites dessas organizações (um de cada um deles) e selecionados de acordo com os seguintes critérios: (1) que tratassem do empreendedorismo social de forma ampla (não consistindo, por exemplo, em notícias ou artigos relativos a algum programa ou evento específico) e (2) que fossem voltados para a orientação dos leitores acerca das práticas que devem ser adotadas para ingressar ou obter sucesso nesse campo. Essa escolha, além de reduzir o universo de textos disponíveis, nos aproxima dos objetivos deste artigo, levando-nos a compreender como essas organizações atuam no sentido de instituir e buscar legitimidade para o campo e apresentar argumentos atrativos para os profissionais, fornecendo ainda modelos de conduta que se estendem a outras esferas da vida social.

Como afirma Fairclough (2001), o desafio é decidir quais amostras são típicas ou representativas de uma certa prática. Essa decisão, ressalta o autor, necessita de um conhecimento geral prévio acerca da "ordem de discurso" da instituição ou domínio que se está pesquisando e dos processos de mudança que estão em andamento. Para tanto, fizemos uma pesquisa exploratória nos referidos sites sustentada pela revisão conceitual sobre o tema "empreendedorismo social" de modo a garantir a representatividade da escolha. Esse "mapa preliminar" foi ampliado com dados suplementares também retirados dos sites dessas organizações, como forma de complementar ou esclarecer algum ponto ou possibilitar comparações entre diferentes situações e contextos.

\section{Endeavor Brasil}

A Endeavor apresenta-se como a “organização líder no apoio a empreendedores de alto

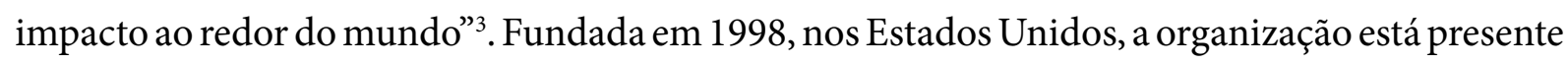
hoje em 22 países, sendo que desde o ano 2000 conta com uma representação no Brasil, onde

2 Por uma questão de espaço não iremos transcrever os textos. Eles podem ser acessados nos links indicados ao longo da discussão.

3 Disponível em: <www.endeavor.org.br>Acesso em: 22 maio 2017. 
possui oito escritórios. Já a Endeavor Brasil foi fundada pelos empresários Beto Sicupira, Jorge Paulo Lemann e Marcel Telles, bilionários brasileiros que comandam o fundo de investimentos $3 \mathrm{G}$ e estão entre os controladores da $\mathrm{AB}$ InBev, empresa resultante da fusão entre Ambev e a belga Interbrew. O artigo selecionado para análise foi publicado no dia 03 de agosto de 2015, no Portal Endeavor Brasil, com o título "Empreendedorismo social: lucro e transformação social

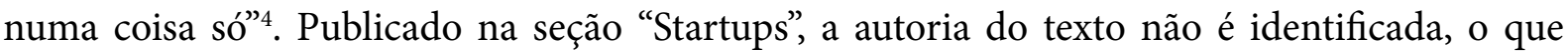
faz com que este possa ser considerado, portanto, como um discurso assumido pela própria organização.

O título do artigo indica qual o seu objetivo principal: explicar para os leitores o que é empreendedorismo social, ou, como fica explícito logo em seguida, no subtítulo, "o que esse conceito quer dizer". O fato de a instituição publicar um texto dessa natureza revela a pressuposição de que esse termo é desconhecido, ou pouco conhecido, por pelo menos uma parte dos leitores que quer atingir. A definição dada, ainda no título, mostra o empreendedorismo social como a junção de dois elementos principais: "lucro" e "transformação social" em uma associação harmônica. Torna-se nítida a intenção do texto, em vários momentos, de desfazer qualquer ideia de contradição entre os dois termos, reforçando, por meio de afirmações categóricas ou de exemplos concretos, a possibilidade de conjugá-los.

Uma das etapas para realização da ACD, como vimos, é a identificação dos participantes do discurso, que incluem tanto aqueles que estão envolvidos na produção, distribuição e recepção do texto, quanto aqueles que participam dos processos que estão sendo descritos. No primeiro caso, o produtor é a própria Endeavor; a distribuição dá-se por meio da disponibilização no site da organização, sem que haja outros intermediários (o mesmo texto, porém, é publicado também nas redes sociais da organização e pode ser replicado por outros veículos de mídia); e os receptores são os leitores do texto, o que, pelas características deste, como vimos, são possíveis interessados em se tornarem empreendedores sociais.

Já os participantes do processo descrito - ou seja, o ato de se tornar um empreendedor social - são (1) pessoas que estão buscando iniciar no mercado de trabalho ou mudar de profissão (as quais podem, inclusive, ser empreendedores "tradicionais" com interesse em mudar de área ou expandir seus negócios, tornando-se empreendedores sociais); (2) aqueles empreendedores sociais que são citados como modelos a serem seguidos; (3) especialistas no assunto, que escrevem artigos para publicações reconhecidas; (4) organizações de apoio ao setor, como incubadoras, aceleradoras, fundos de investimento etc.; (5) a organização de apoio Endeavor, que produz o texto; e (6) os "beneficiários" dos negócios sociais.

Temos, então, dois grupos coincidentes: os leitores, que participam como receptores do texto, são os possíveis interessados em se tornarem empreendedores sociais, que estão por isso buscando informações sobre o tema, como participantes do processo social. Já a relação entre o produtor do texto e os participantes dessa prática social é mais complexa: a Endeavor faz 
claramente parte do grupo das organizações de apoio, mas exerce também o papel de expert no assunto, com autoridade para dar definições e fazer afirmações taxativas sobre o setor, e se aproxima, por meio das posições que assume, do grupo dos empreendedores, adotando, em vários momentos, a perspectiva desses agentes. O tom que predomina no texto é a de uma voz experiente que pacientemente introduz o assunto para leigos, oferecendo dicas, sugestões, referências.

Outro aspecto a ser observado, e que diz respeito sobretudo à dimensão ideacional do discurso, é a transitividade. Esta identifica como os processos são codificados em orações, sendo classificada em quatro tipos principais: relacional (em que o verbo marca uma relação entre os participantes); de ação (quando o agente age em direção a um objetivo explícito - ação dirigida - ou implícito - ação não dirigida); de evento (que envolve um acontecimento); e mental (que diz respeito a processos cognitivos, perceptivos e afetivos).

No texto em análise, predominam os verbos de ação, em que o sujeito é, quase sempre, o empreendedor social: este opta por um caminho, monta um negócio, resolve problemas, quebra paradigmas, contribui para transformar realidades, tem grandes ideias, faz acontecer, cria modelos sustentáveis. Verbos de ação e cognitivos são usados também para descrever os atributos que os receptores do texto devem ter para "se encaixarem no perfil" de empreendedores sociais: superar desafios, lidar com cenários complexos, sonhar em mudar o mundo. Ao tratar da relação entre empreendedores e "beneficiários", os primeiros são os agentes e os segundos os pacientes, mesmo quando se defende que estes últimos devem exercer um papel ativo nos negócios sociais. Assim, os empreendedores devem envolver, apresentar projetos, convidar. Quando os beneficiários são o sujeito da oração, esta tem a voz passiva: devem ser vistos, ser parte inerente das ações.

Há também muitos verbos que indicam eventos e processos mentais: pipocam, inspira, motiva. Nesse caso, os sujeitos das orações não são indivíduos específicos, mas categorias gerais ou entidades abstratas. Há também o uso frequente da voz passiva, em que o agente está oculto - negócios são criados, ideias são colocadas em prática, vidas são transformadas, empregos são gerados, desafios são superados. Ao se referir aos problemas sociais, opta-se por codificar os processos como eventos - cresce a necessidade de fontes de energia renovável - assim como quando se fala do surgimento de empresas específicas - nasce um negócio social.

As metáforas, destaca Fairclough (2001), mais do que adornos estilísticos, estruturam o modo como pensamos determinada realidade. Ele ressalta que algumas metáforas são tão profundamente naturalizadas no interior de uma cultura particular, que as pessoas deixam de percebê-las e se torna difícil escapar delas. No texto em questão, vimos o uso de metáforas cênicas, ligadas ao mundo das artes e do espetáculo, para descrever o empreendedorismo, em expressões como "a arte de empreender", "um novo tipo de empreendedorismo vem ganhando a cena". Há ainda o uso de metáforas geográficas e espaciais para tratar do empreendedorismo social: este é um território, um campo, um caminho, dando-lhe assim materialidade. Quando se 
trata da relação com os beneficiários, usa-se a metáfora da "imersão" e do "mergulho", para dar a ideia de um conhecimento profundo a respeito do tema.

Para ampliarmos a compreensão das estratégias discursivas desenvolvidas nesse texto, podemos recorrer à ideia de regimes de convocação trabalhada por Prado (2013). O autor ressalta que, na vida contemporânea, contamos com uma série de sistemas enunciadores que auxiliam os consumidores a desempenharem diferentes tarefas cotidianas, os quais ajudam o usuário a perceber em que ponto simbólico se encontra e aonde quer chegar - em termos, por exemplo, da administração da vida financeira, da vida amorosa, dos cuidados com o corpo etc. - traçando, a partir daí, os passos e as etapas necessárias.

Dentre esses sistemas, há o que Prado chama de convocadores. Essa convocação atende a "necessidades" de públicos segmentados, mas também ajuda a criá-las, na medida em que, muitas vezes, essas estavam em estado "latente" até que ganhem forma em "tendências" de moda, de busca de futuro, que possam ser satisfeitas por meio de atividades e serviços oferecidos no mercado. No texto em questão, observamos que o empreendedorismo social é oferecido como uma espécie de "mercadoria" que responde aos possíveis anseios dos leitores, mas, ao mesmo tempo, busca produzir essas "necessidades", valorizando os que superaram desafios e sonham em mudar o mundo como modelos ideais de conduta e de "bem viver".

\section{Artemisia}

A Artemisia é uma Organização da Sociedade Civil de Interesse Público (Oscip), fundada em 2004, pela empresária norte-americana Kelly Michel, com o objetivo de apoiar "o desenvolvimento de talentos e empreendedores na criação e desenvolvimento de negócios de impacto que ajudam a resolver os problemas sociais da população de baixa renda no Brasil" A instituição afirma ter sido pioneira na disseminação desse conceito, tendo contribuído para torná-lo mais conhecido no país. Os recursos da Artemisia vêm de um fundo de investimentos, a Potência Ventures (também pertencente a Kelly Michel), de doações espontâneas e da parceria com grandes empresas. A empresária também é uma das sócias, juntamente com os empresários Daniel Izzo e Antonio Ermírio de Moraes Neto', do Vox Capital, "fundo de capital de risco para empresas brasileiras que primam pela redução da desigualdade social"7. Além de atuar na difusão de informações sobre o setor, a organização desenvolve programas de apoio e investimento direto em negócios sociais.

O site da organização disponibiliza, além de informações sobre cada um desses programas, notícias e artigos referentes a temas diversos ligados ao empreendedorismo social

5 Disponível em: <http://projetodraft.com/cansei-de-tornar-os-ricos-ainda-mais-ricos-diz-daniel-izzo-da-vox-capital-que-investe-em-negocios-sociais/> Acesso em: 22 maio 2017

6 Disponível em: <http://projetodraft.com/conheca-a-artemisia-organizacao-ha-10-anos-no-brasil- cuidando-de-quem-quer-cuidar-do-mundo/> Acesso em: 22 maio 2017

7 Disponível em: <http://artemisia.org.br/conteudo/artemisia/historia.aspx> Acesso em: 22 maio 2017 
(eventos, prêmios, pesquisas, criação de novos negócios etc.), tanto produzidos pela própria equipe da plataforma quanto veiculados em outros meios de comunicação. $\mathrm{O}$ artigo analisado foi publicado no site da organização no dia 05 de janeiro de 2015, com o título "Como construir uma carreira com significado?"». O objetivo do texto é apresentar dicas para quem deseja construir uma carreira em negócios sociais. Foi publicado na seção "Conhecimento" do site e, assim como no caso anterior, a autoria do texto não é identificada, sendo, por isso, assumida pela organização.

A primeira dica - "Não separe o profissional do pessoal" - constrói uma imagem do empreendedor social como aquele que une o "comprometimento com uma causa" com "habilidades técnicas e profissionais". Podemos associar essa construção às características do trabalho no capitalismo contemporâneo, tal como descritas por Lazzarato e Negri (2013). Para esses autores, as novas modalidades de trabalho tendem a assumir a forma do trabalho imaterial, até mesmo quando envolvem a produção de bens materiais, tendo em vista que boa parte dos processos produtivos consiste na troca de valores imateriais - informação, conhecimentos, relações e a própria subjetividade. As novas regras, afirmam, flexibilizam as fronteiras entre produção, circulação e consumo e entre o tempo do trabalho e o tempo de vida, ou tempo produtivo e tempo livre. Essa tendência já havia sido percebida também por Boltanski e Chiapello (2009), que veem na noção de "atividade" - e no papel central que esta assume na cidade "conexionista" - a síntese da fusão entre trabalho e não trabalho, entre trabalho remunerado e voluntário.

André Gorz, por sua vez, observa que, no capitalismo contemporâneo, espera-se que os trabalhadores entrem no processo de produção com toda a sua "bagagem cultural". É nesse sentido que o autor fala de uma "mobilização total" das capacidades e das disposições, inclusive as afetivas, de modo que "não nos é mais possível saber a partir de quando estamos 'do lado de fora' do trabalho que somos chamados a realizar" (GORZ, 2005, p. 22). Porém, por mais que as grandes empresas se esforcem para isso, é quase impossível obter de seus "colaboradores" esse engajamento de toda a sua "potência mental e afetiva", uma vez que a própria relação salarial constitui um obstáculo, na medida em que reconhece a separação das partes contratantes e seus respectivos interesses. É esse o limite que o empreendedorismo em geral, e o empreendedorismo social de forma ainda mais pronunciada, busca eliminar, ao suprimir a diferença entre o sujeito e a empresa.

Outra dica é "Não tenha medo do futuro". Vemos aqui que a perspectiva de Boltanski e Chiapello, referente à dimensão de segurança do "espírito do capitalismo", surge como uma questão menor. Em vez de oferecer garantias, os textos do empreendedorismo social desvalorizam a busca por segurança, que aparece como medo de se arriscar. Como se sabe, a aceitação do risco como uma característica da modernidade foi apontada por autores como Giddens (2002)

8 Disponível em: <http://www.artemisia.org.br/conteudo/frentes/conhecimento/interna-conhecimento.aspx?id=211> Acesso em: 22 maio 2017. 
e Beck (2015). Nesse contexto, aceitar o risco é reconhecer que nenhum aspecto das atividades dos indivíduos segue um curso predestinado, estando sempre exposto a acontecimentos contingentes. Viver na "sociedade de risco" implica viver com uma atitude reflexiva perante as possibilidades de ação com que os indivíduos são continuamente confrontados.

Para compreendermos como se dá, no exemplo que estamos analisando, a articulação entre presente e futuro e entre risco e segurança, devemos atentar para o aspecto coesivo. $\mathrm{O}$ texto inicia com perguntas para as quais irá apresentar respostas. Esses questionamentos trazem, como afirma Fairclough (2001), o "mundo da vida" para o texto, ou seja, inserem dúvidas que não são do(s) produtor(es) do texto, mas que se supõe serem dos leitores. As respostas, por sua vez, aparecem na voz não de um especialista técnico - quase não há uso de jargões específicos do campo, o vocabulário utilizado é também próximo do "mundo da vida" - mas de alguém que dá conselhos, que está preocupado com a felicidade e a realização pessoal do leitor, que o motiva a agir.

Todo o texto é organizado em períodos curtos, que iniciam com uma afirmação mais generalizante - tratando de "muitas pessoas" - para em seguida se dirigir diretamente ao leitor - a palavra "você" é usada onze vezes. Dessa forma, transmite-se ao leitor a ideia de que suas insatisfações e receios não são só suas, são compartilhadas por "muitas pessoas" e, portanto, são comuns, "naturais". Porém, o texto as motiva a não se acomodar com essas situações e, dessa forma, se diferenciar desse padrão, tornar-se alguém que não é “qualquer pessoa”, mas sim alguém "extraordinário" que, mesmo diante dos riscos, segue em busca de seus sonhos.

Os verbos utilizados nesse texto mostram uma racionalidade que liga ações aos seus resultados: para atingi-los é preciso agir de certa forma ou evitar certas atitudes. Predomina o modo imperativo e nas orações em que se opta pelo indicativo os verbos são sobretudo relacionais - ser, unir, precisar - e os sujeitos são entidades abstratas: encontrar um trabalho com significado, os negócios de impacto social etc. Essas expressões são também o que Fairclough (2001) chama de "tema", ou seja, elementos que introduzem as orações e trazem informações tácitas, que se supõem conhecidas pelos intérpretes. Assim, pressupõe-se que o leitor deseje encontrar um trabalho com significado e entenda o sentido dessa expressão, bem como presume-se que este sabe de que garantias, incertezas e recompensas o produtor do texto está tratando, ainda que estas não sejam definidas explicitamente.

Vemos aqui o uso da metáfora da construção para definir a trajetória profissional: tratase de construir uma carreira. São também usadas metáforas de deslocamento, com expressões como seguir suas vocações, suas paixões, seus sonhos, explorar suas habilidades ou os passos da transição, além de apresentar o empreendedorismo como um caminho. A liberdade constitui aqui uma nova normatividade: mais do que poder escolher, os indivíduos são obrigados a escolher, e a medir, avaliar e pesar continuamente as consequências de cada uma dessas escolhas (GIDDENS, 2002). Essa "liberdade coercitiva" é apontada por Byung-Chul (2015) como um dos traços centrais da sociedade contemporânea, a que ele denomina "sociedade do desempenho", 
na qual os sujeitos são "empresários de si mesmos”. O paradigma da disciplina é substituído pelo paradigma do desempenho ou pelo esquema positivo do poder.

Assim como no texto anterior, vemos aqui o esforço de apresentar o empreendedorismo social não apenas como uma opção que atenda aos desejos e necessidades dos indivíduos, mas sobretudo em fabricar essas necessidades, criando um "lugar ideal" aonde se deve chegar e para o qual os únicos obstáculos são “interiores”. A representação criada por esse discurso é de que só essa vida com propósito vale a pena ser vivida, em contraste com a vida desperdiçada daqueles que estão presos ao passado, mais preocupados com a estabilidade do que em seguir seu "guia interior".

\section{Ashoka Brasil}

A Ashoka ${ }^{9}$, organização criada em 1980 pelo norte-americano Bill Drayton, define-se como "uma organização mundial, sem fins lucrativos, pioneira no campo da inovação social, trabalho e apoio aos empreendedores sociais - pessoas com ideias criativas e inovadoras capazes de provocar transformações com amplo impacto social" ${ }^{10}$. Ela afirma ser a criadora do termo empreendedorismo social e ter caracterizado este como um campo de trabalho. A organização iniciou sua atuação na Índia e no Brasil (neste último em 1986) e hoje está presente em 85 países. Ela realiza um processo de busca e seleção, com etapas nacionais e internacionais, de empreendedores que "são líderes no campo em que atuam e estão influenciando políticas públicas a fim de gerar mudanças sistêmicas"11. Os selecionados - chamados de "Fellows Ashoka" - passam a integrar uma rede de intercâmbio de informações e colaboração, composta hoje por mais de três mil empreendedores (no Brasil, segundo informações disponíveis no site da organização, são 370 "fellows"). O processo de seleção dos "Fellows Ashoka" está "centrado na pessoa e na solução inovadora de amplo impacto social" e se baseia na avaliação da trajetória pessoal e profissional do candidato, tendo por base os critérios: inovação, perfil empreendedor, criatividade, impacto social e "fibra ética".

O texto que analisamos é intitulado "O terreno escorregadio do investimento de impacto social"12 (a data de publicação deste não é informada no site). O artigo não traz a assinatura do autor e, portanto, como nos casos anteriores, a autoria é assumida pela organização. O objetivo geral do texto não é exposto, logo de início, de forma clara: ele inicia falando do crescimento do empreendedorismo social, em seguida revela preocupação com o fato de que a "ótica do mercado" esteja se sobrepondo às "discussões sobre mudança social", concluindo com três dicas que, entretanto, como veremos, não deixam claro a quem exatamente são dirigidas, se aos

9 O termo Ashoka significa, em sânscrito, "ausência de sofrimento". Disponível em: <http://brasilashoka.org/ quem-somos> Acesso em: 22 maio 2017.

10 Disponível em: <http://brasil.ashoka.org/quem-somos> Acesso em: 22 maio 2017.

11 Disponível em: <http://brasil.ashoka.org/quem-somos> Acesso em: 22 maio 2017.

12 Disponível: <https://www.ashoka.org/pt-br/focus/empreendedorismo-social> Acesso em: 22 maio 2017. 
investidores, aos empreendedores, a ambos ou a um público geral interessado no tema. Por sua vez, se nos detivermos no aspecto coesivo do texto, observamos que este inicia com períodos simples, no presente, que apresentam o empreendedorismo social e os negócios sociais como algo que já é uma realidade: que está na moda.

Analisando os participantes da prática discursiva e dos processos sociais que são descritos no texto, temos, no primeiro caso, o(s) produtor(es) do texto, cuja autoria também não está identificada, e os receptores ou leitores, que, nesse caso, não se restringem a um grupo específico, podendo ser qualquer pessoa interessada, por diferentes motivos, no tema. Como participantes dos processos, temos grupos mais variados: empresas sociais, terceiro setor, investidores, organizações colaborativas, movimentos sociais, legisladores etc.

É importante observar que, nesse texto, a transitividade, ou seja, a codificação dos processos sociais em processos linguísticos, utiliza, em sua grande maioria, verbos que Fairclough (2001) chama de cognitivos, e também, com menor frequência, relacionais: prestar atenção, ganhar atenção, se preocupar, pensar, levar a discussão, acreditar, resolver, conseguir, proteger, evitar, apoiar, ajudar, enfatizar, aceitar, tolerar, aprender etc. Essa característica indica que o texto busca apresentar as percepções e sentimentos que os agentes têm em relação ao empreendedorismo social e, mais do que isso, busca alterá-las, construindo entendimentos positivos e removendo temores ou percepções negativas que possam existir.

O sujeito da maior parte dessas orações ou é um "nós" (oculto ou não), em que não fica claro, porém, quem está incluído (nós, produtores do texto, leitores, empreendedores sociais, investidores), ou são entidades abstratas, como: ascensão meteórica das empresas sociais, o potencial do setor, um novo empreendimento, corrida de investidores, nova geração de empreendedores, o capitalismo.

Assim como a transitividade, a nominalização é outro aspecto que deve ser considerado para a análise da dimensão ideacional do discurso. Esta é a conversão de processos em nomes, o que, em geral, tem o efeito de pôr o processo em segundo plano, não especificando os participantes da ação, de modo que agente e paciente são deixados implícitos. Observamos, no texto em análise, uma grande presença de nominalizações: investimento, ascensão, entusiasmo, preocupação, conversa, corrida, discussão, mudança, impacto. Fairclough (2001) observa que esse recurso é uma característica frequente na linguagem científica e técnica, podendo soar ameaçadora ou mistificadora para pessoas leigas.

Outro aspecto da análise proposta por Fairclough (2001), e que se torna particularmente relevante neste caso, é o tema, ou a parte inicial da oração, o ponto de partida do produtor do texto numa oração e que geralmente corresponde ao que pode ser considerado "informação dada", ou seja, informação já conhecida para os produtores e intérpretes do texto. Segundo Fairclough (2001), examinar o que tende a ser selecionado como tema em diferentes tipos de texto ajuda a compreender os pressupostos do senso comum a respeito da ordem social e as estratégias retóricas. 
Ao trazer para o início das orações, por exemplo, a ascensão meteórica das empresas sociais e a existência de investimentos de impacto social, e a adjetivação desses fatores como "ótimas notícias", o produtor do texto coloca essas informações como sendo de conhecimento comum dos leitores e intérpretes, como fatos que não precisam ser explicados ou questionados. Mesmo quando busca introduzir as preocupações de determinado grupo (as organizações sem fins lucrativos), as orações iniciam com expressões positivas que mostram o crescimento do empreendedorismo social.

Enquanto, ao tratar dos problemas sociais, há o uso predominante da voz passiva e da nominalização, que ocultam o agente, quando se trata de apontar como esses agentes devem agir há o uso da voz ativa com o sujeito "nós". Esse recurso suaviza os imperativos dados, na medida em que não se está dizendo a terceiros o que esses devem fazer, o que poderia ser interpretado como uma postura autoritária, e sim dando conselhos que servem para os próprios produtores do texto, enquanto parte desse "sujeito plural" abrangente e indefinido, personificação da totalidade harmônica que os discursos do empreendedorismo social se esforçam em criar.

\section{Análise comparativa e conclusiva}

Podemos fazer uma análise comparativa dos três textos focalizando palavras-chave que aparecem em destaque em cada um deles, todas ligadas ao campo semântico do empreendedorismo social. Como ressalta Fairclough (2001), a relação entre palavras e significados é de muitospara-um e não de um-para-um, ou seja, cada palavra pode assumir diferentes significados no texto e cada significado pode ser lexicalizado de diferentes formas.

Fairclough (2001) chama a gama de significados convencionalmente associados a uma palavra de significado-potencial, cuja representação mais conhecida são os verbetes dos dicionários. Porém, o modelo de organização do dicionário implica em uma concepção de significado na qual se considera que o significado-potencial é estável e universal, ou seja, comum a todos os membros de uma comunidade de fala e, mais do que isso, de que os significados contidos no significado-potencial (ou seja, as diferentes definições de uma mesma palavra) são descontínuos, claramente demarcados entre si e mutuamente exclusivos (ou um ou outro). Sobretudo nos processos de mudança social e cultural, essa concepção pode não corresponder à realidade: a relação palavra-significado pode ser instável, envolvendo disputas entre atribuições conflitantes de significados. Estas, por sua vez, podem resultar em mudanças na força e na clareza de limites entre os significados, os quais podem estar em uma relação de complementaridade ou hierárquica, de modo que um significado se impõe sobre os demais.

Assim, os textos - sobretudo os textos que Fairclough (2001) chama de criativos, ou seja, que tratam o significado-potencial não como um código a seguir, mas como um recurso explorável e em mutação - trazem ambiguidades e ambivalências, realizando um jogo retórico com os potenciais das palavras, que alteram os limites e as relações entre significados. Tomando 
como exemplo o uso da palavra "empreendimento", o autor observa que esta tem três sentidos que compõem seu significado-potencial: atividade, negócio e qualidade (que podem ser qualidades especificamente ligadas a atividades empresariais, mas também qualidades pessoais mais gerais).

Usamos esse modelo para analisar os significados atribuídos às palavras-chave que aparecem em destaque nos três textos escolhidos para este estudo. O primeiro texto, da Endeavor, tem como expressão central "empreendedorismo social"; o segundo, da Artemisia, articula-se em torno do termo "negócios de impacto social"; e o terceiro, da Ashoka Brasil, elege como núcleo a expressão "investimento de impacto social". A escolha desses diferentes termos não é ocasional. Ela diz respeito tanto aos discursos dessas organizações em geral quanto aos objetivos dos textos especificamente. Observamos, assim, que enquanto Endeavor e Ashoka usam frequentemente o termo empreendedorismo social em seus textos, a Artemisia opta preferencialmente por negócios de impacto social, o que pode ser visto como uma estratégia desta para se diferenciar, tendo em vista que afirma ter sido pioneira na disseminação desse conceito.

Essa diferença de vocabulário está ligada à multiplicidade de meios para expressar com novas palavras um significado, ou seja, à lexicalização. Não se deve, porém, ter o entendimento equivocado de que existem significados previamente existentes, que são postos em diferentes palavras. O que há são formas alternativas de significar - e lexicalizar - domínios particulares da experiência. Essas diferentes formas de expressão traduzem perspectivas teóricas, culturais e ideológicas distintas e, também, levam a diferentes interpretações, pois, como afirma, "quando se troca a palavra também se troca o significado" (FAIRCLOUGH, 2001, p. 236).

Podemos verificar isso observando as palavras-chave - ou itens lexicais - usadas em cada um dos textos. No primeiro, além do já citado empreendedorismo social, vemos palavras como: lucro, transformação, negócios, ideias, empregos, desafios, responsabilidade social, produtos, serviços, modelos de negócios, empresas, organizações, escassez, crises, racionamento, recursos, modelos financeiros, equilíbrio, beneficiários-alvo, projetos, demanda, público-alvo, ferramentas, plano de marketing, proposta de valor, estrutura de custos, indicadores, impacto, solução, validação, fontes de informação, consumidor, financiadores. O vocabulário usado é sobretudo da administração de empresas. Nesse caso, o significado de empreendedorismo é principalmente de uma atividade. É uma categoria que envolve iniciativas, escolhas, montagem de negócios, resolução de problemas, venda de produtos e serviços. Ainda que se faça referência explícita a negócios específicos, o que é exaltado aqui é a atividade geral do empreendedorismo, descrita como ter grandes ideias e fazer acontecer.

No segundo texto, além de negócios de impacto social, temos o uso de palavras como: carreira, dinheiro, profissional, pessoal, trabalho, paixão, indignação, pessoas, habilidades, mercado, escolhas, realização, sucesso, propósito, organização, talento, vocações, paixões, garantias, incertezas, recompensas, transição, preferências, surpresas, segurança, atividade, risco, sonhos, empregos. Nesse caso, o significado que se sobressai é o de qualidade. $\mathrm{O}$ vocabulário usado é mais próximo da vida cotidiana e está ligado a qualidades pessoais ou 
estados emocionais. Negócios de impacto social são, assim, ligados às qualidades culturalmente valorizadas de "espírito empreendedor" e das pessoas que são "preocupadas com o social" e movidas por uma causa e que, mesmo que se preocupem com sua segurança, não deixam de agir temendo os riscos, atendendo aos apelos dos seus sonhos e vocações.

No terceiro texto, além de investimento de impacto social, temos palavras e expressões como ascensão, potencial, entusiasmo, dúvida, preocupação, receitas, corrida de investidores, nova geração de empreendedores, ótica do mercado, lógica de mercado, produto ou serviço vendável, empresas individuais, capitalismo, pobreza, desastres naturais, direitos humanos, abusos, mudanças políticas, regulamentações, movimentos sociais, filantropia, lucro, sucesso, retorno financeiro, equação, métricas, ferramentas, resultado, expectativas, taxa de lucros, risco, perda, missão social, mercado, área emergente, foco, objetivo, eficiência, classe de ativos. Nesse caso, o investimento de impacto social é significado sobretudo como negócio, ou como um setor de negócios. São negócios que geram receitas, que produzem um produto ou serviço vendável, que geram lucro e retorno financeiro. O vocabulário utilizado é ainda o da administração de empresas, mas também o da economia, sendo o único que fala de capitalismo, pobreza, mercado, ativos e que traz, ainda que implicitamente, a ideia de concorrência.

Essas diferentes abordagens e mudanças de vocabulários mostram como os discursos do empreendedorismo social podem ser investidos de diferentes significados, de acordo com as estratégias dos diferentes textos. Assim, o empreendedorismo social é descrito como uma atividade (ou um conjunto de várias atividades), que se apresenta como um tipo do empreendedorismo geral, e que está ligado às iniciativas individuais e à transformação social, como uma força impulsionadora não só da economia, mas da prosperidade social.

Além disso, aparece como uma qualidade quando é apresentado como uma opção profissional para aqueles que estão iniciando no mercado de trabalho ou que desejam mudar de carreira. Nesse caso, são exaltadas as qualidades dos criadores ou daqueles que trabalham em negócios de impacto social, como pessoas vocacionadas, talentosas e comprometidas, em contraste com as pessoas que se acomodam com empregos bem-remunerados, mas que não se realizam plenamente "como seres humanos", por não terem "um propósito".

E, por fim, é tratado como um negócio quando se trata de falar com investidores, para quem o que interessa são taxas de retorno e resultados financeiros, ao mesmo tempo em que esse discurso da economia é utilizado para demarcar a fronteira entre os negócios sociais e as organizações sem fins lucrativos, sendo estas colocadas em uma relação de subordinação àqueles: devem se contentar em atuar nas poucas áreas em que é "muito difícil gerar lucro".

A partir da análise comparativa feita acima, podemos concluir que o empreendedorismo social é um campo discursivo móvel, cujas fronteiras estão sendo permanentemente deslocadas pelas ações de seus múltiplos agentes. A ambiguidade que marca os discursos evidencia o caráter até certo ponto arbitrário da designação "social", utilizada para nomear um conjunto vasto e diverso de agentes, práticas e organizações como uma espécie de distintivo simbólico 
que teria o dom de dotar de um objetivo mais nobre e elevado - porque subordinado a fins "altruístas" ou "coletivos" - as atividades econômicas tradicionais. Parece-nos pertinente, então, considerar que o empreendedorismo social se apresenta como uma inovação dentro do próprio empreendedorismo - sobretudo pela abertura de um novo mercado, aquele formado pelos "problemas sociais", mas também pelo desenvolvimento de novos produtos (a partir dos avanços tecnológicos) e de novos métodos de gestão e organização que adotam, anunciados como capazes de gerar benefícios sociais imediatos.

Observamos o esforço das organizações de apoio pesquisadas (Endeavor Brasil, Artemisia e Ashoka Brasil) em instituir discursivamente esse campo, dotando-o de reconhecimento e "materialidade". Esse trabalho se dá, em grande parte, por meio da construção e difusão de argumentos que visam apresentá-lo como uma "realidade", personificada em iniciativas pontuais que se tornam casos exemplares, mas também como uma projeção futura, o que se expressa, no vocabulário típico desse segmento, na forma de um "potencial” revolucionário de que estariam imbuídos os "negócios sociais". O empenho destas organizações está direcionado, portanto, para construir uma representação do empreendedorismo social como uma oportunidade para novos profissionais e para aqueles que, mesmo já possuindo uma "carreira", mostram-se insatisfeitos com esta, justamente pela falta de um "propósito" ou de um "sentido maior" que funcione como força motivadora eficaz.

Esse papel relaciona-se àquele atribuído por Boltanski e Chiapello (2009) ao novo espírito do capitalismo, ou seja, às razões morais que justificam o engajamento nas práticas capitalistas, com fundamento num ideal de bem comum. Este se manifesta, aqui, em duas dimensões. Há, num primeiro plano, o estímulo ao investimento no empreendedorismo social como alternativa para aqueles que "não se encaixam" nos modelos de empresa tradicionais e/ou que manifestam uma postura crítica em relação a esses. E, tomado em uma dimensão mais ampla, esse tipo de empreendedorismo fornece também uma justificativa moral para o capitalismo como um todo, tendo em vista que posiciona o setor privado como a força salvadora a partir da qual podem emergir as soluções inovadoras para os problemas sociais, soluções estas que nem o poder público nem as organizações do terceiro setor mostraram-se, de acordo com esses discursos, capazes de alcançar.

\section{Referências}

BECK, Ulrich. Sociedade de risco mundial: em busca da segurança perdida. Rio de Janeiro: Edições 70, 2015. BOLTANSKI, Luc; CHIAPELLO, Ève. O novo espírito do capitalismo. São Paulo: Martins Fontes, 2009. BYUNG-CHUL, Han. Sociedade do cansaço. Petrópolis-RJ: Vozes, 2015.

CASAQUI, Vander. Esboços e projetos da sociedade empreendedora: mundo conexionista, sociabilidade e consumo. Revista Famecos, Porto Alegre, v. 23, n. 3, p. 1-18, set/dez 2016a. Disponível em: <http://revistaseletronicas. pucrs.br/ojs/index.php/revistafamecos/article/view/22654/14611> Acesso em: 22 maio 2017. 
CASAQUI, Vander. A transformação social nos discursos da cena empreendedora social brasileira: processos comunicacionais e regimes de convocação na mídia digital. Universitas Humanística, Bogotá, n. 81, p. 205-226, jan/jun 2016b.Disponível em: <http://www.scielo.org.co/scielo.php?script=sci_abstract\&pid=S0120-48072016000100009> Acesso em: 22 maio 2017.

CHIAPELLO, Ève; FAIRCLOUGH, Norman. Understanding the new management ideology: a transdisciplinary contribution from critical discourse analysis and new sociology of capitalism. Discourse \& Society, London, Thousand Oaks, New Delhi, v. 13, n. 2 p. 185-208, 2002.Disponível em:<http://journals.sagepub.com/doi/abs/10.1177/0 957926502013002406> Acesso em: 22 maio 2017.

DARDOT, Pierre; LAVAL, Christian. A nova razão do mundo. Ensaio sobre a sociedade neoliberal. São Paulo: Boitempo, 2016.

DEES, J. Gregory. The meaning of social entrepreneurship. Kansas City: Kauffman Foundation and Stanford University, 1998.

DEY, Pascal; STEYAERT, Chris. The politics of narrating social entrepreneurship. Journal of Enterprising Communities: Peoples and Places in the Global Economy. v. 4, n. 1, p. 85-108, 2010. Disponível em: <https://www. alexandria.unisg.ch/61556/1/Dey\%20Steyaert\%202010\%20JEC.pdf> Acesso em: 22 maio 2017.

FAIRCLOUGH, Norman. Discurso e mudança social. Brasília: UnB, 2001.

FOUCAULT, Michel. Naissance de la biopolitique. Cours au Collège de France (1978-1979). Paris: Seuil/Gallimard, 2004.

GIDDENS, Anthony. Modernidade e identidade. Rio de Janeiro: Zahar, 2002.

GORZ, André. O Imaterial: Conhecimento, Valor e Capital. São Paulo: Annablume, 2005.

GROS, Frédéric. Desobedecer. São Paulo: Ubu Editora, 2018.

HERVIEUX, Chantal; GEDAJLOVIC, Eric; TURCOTTE, Marie-France B. The legitimization of social entrepreneurship. Journal of Enterprise Communities: People and places in the global economy, v. 4, n. 1, p. 37-67, 2010. Disponível em: <http://www.sfu.ca/ erg/research/chantal> Acesso em: 22 maio 2017

IRIGARAY, Hélio A. R.; CUNHA, Gustavo X.; HARTEN, Bruno A. Missão organizacional: o que a análise crítica do discurso revela? Cardernos EBAPE.Br, Rio de Janeiro, v. 14, n. 4, p. 920-933, out./dez. 2016. Disponível em: <http://www.scielo.br/pdf/cebape/v14n4/1679-3951-cebape-14-04-00920.pdf> Acesso em: 22 maio 2017.

LAZZARATO, Maurizio; NEGRI, Antonio. Trabalho imaterial: formas de vida e produção de subjetividade. Rio de Janeiro: Lamparina, 2013.

PARENTE, Cristina Clara Ribeiro; BARBOSA, Allan Claudius Queiroz. Empreendedorismo social: do contexto político às práticas de implementação - um estudo de experiências no Brasil e sua aproximação à realidade de Portugal. In: ENCONTRO DA ANPAD, 35, Rio de Janeiro. EnANPAD, Rio de Janeiro, 2011. p. 1-17. Disponível em: <http://www.anpad.org.br/admin/pdf/GCT1105.pdf> Acesso em: 22 maio 2017.

PRADO, José Luiz Aidar. Convocações biopolíticas dos dispositivos comunicacionais. São Paulo: Educ/Fapesp, 2013.

Recebido em: 20/03/2018 